\title{
IRRETROATIVIDADE LEGAL E JURISPRUDENCIAL A \\ PARTIR DO PACTO INTERNACIONAL SOBRE DIREITOS \\ CIVIS E POLÍTICOS: DIALOGANDO COM A CONSTITUIÇÃO \\ DA REPÚBLICA
}

\author{
LEGAL AND JURISPRUDENTIAL NON-RETROACTIVITY BASED ON THE \\ INTERNATIONAL COVENANT ON CIVIL AND POLITICAL RIGHTS: \\ DIALOGUING WITH THE CONSTITUTION OF THE REPUBLIC
}

\section{RESUMO}

O presente trabalho tem como objetivo principal analisar criticamente a retroatividade da lei e da jurisprudência penal, sobretudo quando mais prejudiciais, tendo como ponto de partida o Pacto Internacional sobre Direitos Civis e Políticos (artigo 15). Articular os argumentos mais relevantes que são apresentados sobre a temática no contexto brasileiro é também uma de nossas propostas. Com base numa pontual revisão bibliográfica procuramos apontar as implicações que o tema pode vir a ter diante da necessidade de se efetivar a proteção dos direitos humanos. A Suprema Corte brasileira, em nossa perspectiva, tem falhado no exercício de seu principal mister, como guardião dos valores democráticos tutelados na Constituição da República de 1988. Desse modo, concluímos pela necessidade de se adotaro mesmo entendimento já muito bem sedimentado quanto à irretroatividadeda lei penal também para a jurisprudência penal mais prejudicial.

Palavras-chave: Irretroatividade. Lei penal. Jurisprudência penal. Valores democráticos.

\section{ABSTRACT}

\footnotetext{
${ }^{1}$ Doutorando e Mestre em Direito pela Universidade de Coimbra (PT), Professor no Centro Universitário CESMAC (Maceió/AL), Coordenador Adjunto do Instituto Brasileiro de Ciências Criminais em Alagoas, Advogado de defesa. ${ }^{2}$ Doutorando em Direito pela PUC/RS. Mestre em Direito Público pela Universidade Federal de Alagoas - UFAL. Professor no Centro Universitário CESMAC (Maceió/AL) e na Faculdade de Ciências Sociais e Jurídicas de Maceió - FAMA. Coordenador do Instituto Brasileiro de Ciências Criminais - IBCCrim em Alagoas. Advogado.
} 
The main objective of this paper is to critically analyze the retroactivity of law and criminal jurisprudence, especially when they are most harmful, taking as a starting point the International Covenant on Civil and Political Rights (article 15). Articulating the most relevant arguments that are presented on the subject in the Brazilian context is also one of our proposals. Based on a punctual bibliographic review, we seek to point out the implications that the theme may have in view of the need to effectively protect human rights. The Brazilian Supreme Court, in our perspective, has failed to exercise its main task, as guardian of the democratic values protected by the 1988 Constitution of the Republic. Thus, we conclude that it is necessary to adopthe same understanding, already well established on the non-retroactivity of criminal law, also for the most harmful criminal jurisprudence.

Key words: Non-retroactivity. Criminal law. Criminal jurisprudence. Democratic values.

\section{INTRODUÇÃO}

O Pacto Internacional sobre Direitos Civis e Políticos, adotado e aberto à assinatura, ratificação e adesão pela Resolução 2200-A (XXI) da Assembleia Geral das Nações Unidas, de 16 de dezembro de 1966, em linhas gerais, surge com a pretensão dereforçar o discursosobre a efetividade dos direitos humanos no período do pós Segunda Grande Guerra.Preocupa-se, muito especialmente, em asseguraros direitos referidos na Declaração Universal dos Direitos Humanos,de 1948. É, portanto, a partir daí que seintensificam os movimentos de elevação de inúmeros direitosreconhecidos como humanos à categoria de fundamentais.

Nesse contexto, percebe-se claramente que as intenções dispostas no pacto, sobretudo em matéria penal,foram acolhidas pelaCarta Constitucionalem 1988. Ocorre que, dada a amplitude das questões discutíveis nesse processo de recepção, não haveremos de nos debruçar sobre o todo.Oobjeto específico de nosso estudorecairá, portanto, sobre as possibilidades e a questão da temporalidade, não apenas da lei penal,mas também de sua jurisprudência,para verificação de legitimidadena produção de efeitos jurídicos.A questão central será: podem ser aplicadas a fatos que não ocorreram sob suas vigências?

Nossa construção teórico-argumentativaestará vinculadaaos postulados de conformação com o Estado de Direito democrático, cuja fundação deve-se, principalmente, ao respeito à legalidade.Esta, aliás, como sabemos, funciona como garantia fundamental de proteção do indivíduo frente a eventuais abusos tanto por parte dos poderes constituídosquanto dos seus semelhantes.Institucionalizou-se a previsibilidade da norma penal como referencial a ser seguido, promovendo-se a segurança jurídica, evitando-se, assim, alterações inconvenientes que não refletem os valores assimilados ao tempo da conduta que se quer como desviante. 
Apesar da aparente simplicidade, a temática nos exige, a partir do mencionado pacto, averiguar como se deu a institucionalização do princípio da irretroatividade de lei penal mais graveno Brasil.Sua conformidadeconstitucional eseu vínculo com o princípio da legalidade estarão em nosso radar. Revisitar esse tema é uma providência que se impõe, sobretudo quando já se tem admitido no país a retroatividade de mudança jurisprudencialmesmo quandoprejudicial ao réu. Daí queprecisamosrecordar como esses critérios se colocamcomo limitesao funcionamento do sistema, remetendo-nos àsensível temáticado tempo do crime.

Ao final desse percurso, partindo-se de pontuais revisões bibliográficas, forçoso concluirmos que a estabilidade da ordem jurídica democrática só há de se sustentar se os critérios outrora erigidos a partir da comunidade internacional forem devida e absolutamente restaurados no âmbito do entendimento majoritário do Supremo Tribunal Federal, que, surfando na onda do direito penal midiático $^{3}$, ao invés de se assumir como um rigoroso guardião dos valores democráticos, tem se posicionado, nos últimos tempos, como aquele simpático porteiro que, não raramente,permite-se envolver pelacantilena de estranhosao ambiente que protege.

\section{A IRRETROATIVIDADE DE LEI PENAL MAIS GRAVOSA COMO GARANTIA} PRESCRITA A PARTIR DO PACTO INTERNACIONAL SOBRE DIREITOS CIVIS E POLÍTICOS

Com o fim da Segunda GuerraMundial,em 1945, apurados os prejuízos sócio-econômicos que os conflitos haviam provocado, constatou-sea necessidade de se manter alguma regularidade nas relações, sobretudo comerciais, entre os países do globo.Naquele mesmo ano surgia a Organização das Nações Unidas. Estruturou-se um sistema perene de prevenção de conflitos, bem como de (alegada) proteção dos direitos humanos. Nascia, portanto, um órgão que pudesse congregar todos os países e que tivesse a capacidade de assumir protagonismo na construção de uma rede de fomento à convivência civilizada entre os povos.

Não por acaso,o Pacto Internacional sobre Direitos Civis e Políticos, recepcionado no Brasil a partir do Decreto n. 592/1992, de 6 de julho, objetivou dar efetiva aplicabilidade a direitos que se pressupunham inerentes aos seres humanos. Direitos compreendidos por básicos, como, por exemplo, a autodeterminação dos povos, a igualdade (formal e material) entre todas as pessoas, a

\footnotetext{
${ }^{3}$ Cujas construções da narrativa e da resposta sobre o fato encarado como crime são geralmente determinadas não a partir de critérios jurídico-dogmáticos, mas dos interesses da mídia de massa, estando a mesma mais preocupada em atrair a atenção popular (o que também vai atrair anunciantes e, portanto, possibilidade de lucro) do que propriamente em resolver os conflitos judicializados.
} 
garantia da proteção à vida, à liberdade, a proibição da tortura e dos trabalhos forçados (PORTELA, 2011, p. 724), dentre tantos outros reconhecidos como humanos, enfatizando-se especialmenteaquelesjá consagradosna Declaração Universal dos Direitos Humanos.

Avançadas as discussões sobre um arcabouço normativo que permitisse, além da unidade, alguma efetividade às pretensões dessa rede de cooperação mútua, fertilizou-se o terreno para o nascimento da Convenção de Viena, em 1969, que tratou de estabelecer uma espécie de "direito dos tratados", com regras para o cumprimento das obrigações assumidas internacionalmente pelos países (pacta sunt servanda). O Brasil, evidentemente, não ficou alheio a essa dinâmica internacional, tendo ratificado a referida convenção em 2009, através do Decreto n. 7.030/2009, de 14 de dezembro. ${ }^{4}$

Esse, aliás,é operíodo da "fase legislativa" (WEIS, 2006, p. 44) dos tratados.Naquele momento, também foi promulgado o Pacto Internacional sobre Direitos Econômicos, Sociais e Culturais (1966). Enquanto o primeiro se referia aos direitos de origem liberal, este é basicamente oriundo dos movimentos sociais do século XIX, intensificados a partir das mudançaspromovidas pela Revolução Industrial. É nesse contexto histórico que aflora o interesse pela concretização de uma dupla função estatal diante da dinâmica social moderna:da perspectiva negativa, o de respeitar determinados direitos; e daperspectiva positiva, o de atuar para protegê-los (FELDENS, 2008, p. $58)$.

Não obstante a necessidade em delimitar nosso objeto de análise, pareceu-nos imprescindível o sucinto excurso histórico até aqui levado à cabo.O fato é que, a adesão às características essenciais da legalidade em ambiente democrático, das quais trataremos mais adiante, deve-se, sobretudo, às condições criadas por esse contexto histórico. O respeito à legalidade, e tudo que a acompanha, não se trata, portanto, de uma mera opção das autoridades nacionais, mas do respeito a um compromisso internacional que sequer pode ser obstaculizado com base no direito interno. ${ }^{5}$

A construção dogmática da legalidade,que regulará aquela atuação (negativa ou positiva) estatal, costuma ser associada historicamente à Paul Johann Anselm von Feuerbach.No início do século XIX sua tradução era normalmente apresentada pela expressão nullum crimen, nulla poena sine lege. Reservou-se apenas à lei a criação de um tipo legal de crime. Embora recaia sobre o mencionado autor, tal entendimento, não nos custa lembrar, já havia sido formulado, ainda que incipientemente, na MagnaCharta, no Bill of Rights, no opúsculo de Beccaria, e na Declaração

\footnotetext{
${ }^{4}$ Apesar do compromisso assumido, já devidamente incorporado ao direito interno, ainda existem controvérsias sobre seu lugar na hierarquia normativa. (LOPES; LOPES, 2016)

${ }^{5}$ Sobre esse dever inescusável, vejam-se os artigos 26 e 27 da Convenção de Viena.
} 
dos Direitos do Homem e do Cidadão proveniente da Revolução Francesa. (TOLEDO, 1994, p. 21-22)

Essa legalidade, entendida - a traço grosso - como garantia de qualquer cidadão frente aeventuais abusos, especialmente aqueles que poderiam partir do próprio poder instituído, desdobra-se em outras garantias ou subprincípios, também traduzidas em conhecidas expressões latinas: nullum crimen, nulla poena sine lege praevia; nullum crimen, nulla poena sine lege scripta; nullum crimen, nulla poena sine lege stricta, e; nullum crimen, nulla poena sine lege certa. Não obstante a riqueza de seu conteúdo, nosso focodentro dessa alargada ideia sobre a legalidade, como já antevisto, residirá na imposição da lexpraevia.

Nesse passo, a irretroatividade da lei penal mais gravosa,para irmos direto ao ponto,surge como consequência lógica da adoção da legalidade como uma das bases principais do Estado moderno. Era preciso estabelecer limites aos detentores do poder punitivo. Toda essa estrutura de freiose contrapesos, a partir do século XX, é, ainda que de maneira incipiente, concebida sobre o conceito do Estado de Direito. Seus órgãos só poderiam atuar por intermédio de uma habilitação jurídica, seus poderesestão fundados em normas jurídicas, que lhes concebemlegitimidade para atuações de maneira previamente regrada. (CHEVALLIER, 2013, p. 14)

Dito sucintamente, apenas para que não percamos de vista lições comezinhas, os indivíduos delegam parcela de seus alegados poderes a representantes que elegem.Estes, por sua vez,personificam o Estado, incumbem-se de criar as normas que devem reger a dinâmica social, erigindo-se assim as basespara um ambienteque se pretende democrático.Deve haver, portanto,uma submissão de todos, inclusive dos representantes do povo, àsnormas colocadas em vigência.Estas, por seu turno, devem se submeter à Constituição e aos compromissos regionais e internacionais com os quais se relacionam.

É nesse contexto que o artigo 15 do Pacto Internacional sobre Direitos Civis e Políticos ${ }^{6}$ dialogacom os incisos XXXIX e XL do art. $5^{\circ}$ da Constituição da República. ${ }^{7}$ Além

\footnotetext{
${ }^{6}$ Artigo $15-1$. ninguém poderá ser condenado por atos omissões que não constituam delito de acordo com o direito nacional ou internacional, no momento em que foram cometidos. Tampouco poder-se-á impor pena mais grave do que a aplicável no momento da ocorrência do delito. Se, depois de perpetrado o delito, a lei estipular a imposição de pena mais leve, o delinqüente deverá dela beneficiar-se. 2. Nenhuma disposição do presente Pacto impedirá o julgamento ou a condenação de qualquer individuo por atos ou omissões que, momento em que forma cometidos, eram considerados delituosos de acordo com os princípios gerais de direito reconhecidos pela comunidade das nações.

${ }^{7}$ Art. $5^{\circ}$. Todos são iguais perante a lei, sem distinção de qualquer natureza, garantindo-se aos brasileiros e aos estrangeiros residentes no País a inviolabilidade do direito à vida, à liberdade, à igualdade, à segurança e à propriedade, nos termos seguintes: [...] XXXIX - não há crime sem lei anterior que o defina, nem pena sem prévia cominação legal; XL - a lei penal não retroagirá, salvo para beneficiar o réu;
} 
disso, mesmo que não explicitamente, serve-nos de reforço o art. $2^{\circ}$ do Código Penal brasileiro. ${ }^{8}$ Logo, o ordenamento jurídico brasileiro, ao menos nesse particular,conforma-se como padrão estabelecido pela comunidade internacional. Desde a Declaração Universal dos Direitos Humanos (art. 11, item 2), ${ }^{9}$ passando até pelo Pacto de São José da Costa Rica (art. $9^{\circ}$ ), ${ }^{10}$ expressa-se a possibilidade de retroatividade de lei penal apenas quando benéfica. (CALLEGARI, 2013, p. 388)

Por via de consequência, a proibição daretroatividade de lei penal mais gravosa demonstra uma clara garantia individual de toda e qualquer pessoa contra abusos estatais.Mudanças nas regras do jogo da persecução podem até ocorrer, mas só serão admitidas como válidas para fatos já ocorridos quando trouxerem benefícios. Em resumo: os prejuízos de uma mudança legislativa não podem ser suportados por quem nãos os tinha em seu horizonte quando protagonizou o fato.Sem tal vedação poderíamos ter uma burla à legalidade. Éo que, aliás,reforça sua essência de garantia à proteção de direitos humanos e fundamentais. (MUÑOZ CONDE, 2001, p. 153)

Desse modo, a validade da legislação penal estávinculadaà sua conformaçãocom os diversos intrumentos normativos até aqui mencionados.São, portanto, nosso referencial obrigatório,quer seja no âmbitodo legislativo,quer seja no executivo ou, com veremos no próximo capítulo,no judiciário.Diante do emaranhado de previsões, escolhemos o Pacto Internacional sobre Direitos Civis e Políticos como referencial de partida não apenas por conta da vedação expressa da irretroatividade de lei penal mais gravosa, o que, como vimos, também se constata em outros intrumentos, mas por sua significativa dimensão no contexto histórico.

Para que se tenha uma ligeira ideia dessa importância, segundo a perspectiva de Manuel Diez de Velasco (1996, p. 231, tradução nossa), ambos os pactos representaram "uma mudança qualitativa no tratamento dos Direitos Humanos, por se tratarem de instrumentos convencionais

\footnotetext{
${ }^{8}$ Art. $2^{\circ}$ - Ninguém pode ser punido por fato que lei posterior deixa de considerar crime, cessando em virtude dela a execução e os efeitos penais da sentença condenatória. Parágrafo único - A lei posterior, que de qualquer modo favorecer o agente, aplica-se aos fatos anteriores, ainda que decididos por sentença condenatória transitada em julgado.
}

\footnotetext{
${ }^{9}$ Art. $11-[\ldots]$ 2. Ninguém poderá ser culpado por qualquer ação ou omissão que, no momento, não constituíam delito perante o direito nacional ou internacional. Também não será imposta pena mais forte do que aquela que, no momento da prática, era aplicável ao ato delituoso.

${ }^{10}$ Artigo $9^{\circ}$ - Princípio da legalidade e da retroatividade - Ninguém poderá ser condenado por atos ou omissões que, no momento em que foram cometidos, não constituam delito, de acordo com o direito aplicável. Tampouco poder-se-á impor pena mais grave do que a aplicável no momento da ocorrência do delito. Se, depois de perpetrado o delito, a lei estipular a imposição de pena mais leve, o deliquente deverá dela beneficiar-
} se. 
que impõem obrigações jurídicas vinculantes diretamente aos Estados-partes" ${ }^{\text {"11 }}$. No entanto - ao contrário do Pacto sobre Direitos Econômicos, Sociais e Culturais -, o Pacto sobre Direitos Civis e Políticos impôs obrigações do tipo automáticas, obrigando-se o Estado a reconhecer e a garantir imediatamente os direitos ali prescritos.

Por fim, o que constatamosé uma decorrência do próprio desenvolvimento da estrutura organizacional do Estado moderno, afastando-se o arbítrio dos governos absolutistas por intermédio de uma filosofia baseada no individualismo, em que as instituições deveriam refletir os interesses dos indivíduos e protegê-los (KERSTING, 2003, p. 42).É justamente esse individualismo normatizadoatravés da legalidade, vinculado ao igualitarismo eà taxatividade dos direitos, que apresenta uma ideia de procedimentalismo como teoria de justificação (KERSTING, 2003, p. 49), em que qualquer ruptura posterior ao fato criminoso, no sentido de enrijecer a reprimenda, se torna ilegítima.

Evidentemente que, por outro lado, a retroatividade de lei penal que beneficia encontra também seu fundamento na principiologia básicado direito penal do Estado moderno, dito liberal.Se este deve regular penalmente apenas situações conflituosas excepcionais (como ultima ratio e, portanto, subsidiário), qualquer modificaçãono conteúdo do tipo legal de crime,a ponto de considerar menos grave determinadocomportamento, demonstra uma clara necessidade lógica de atuação menos intensa (ou até de não atuação) desse mesmo ramo do direito sobre os supostamente envolvidos com aquele tipo de fato. (ZAFFARONI; PIERANGELI, 2015, p. 211)

Conquanto, não percamos de vista a ultratividade de leis temporárias ou excepcionais, situações em que,conforme prescreve o art. $3^{0}$ do Código Penal brasileiro, ${ }^{12}$ mesmo que esgotadaa vigência, terão aplicação para fatos ocorridos durante aquele período.Logo, mesmo com o fim da vigência prefixada, o fato deve permanecer atrelado aos seus efeitos jurídico-penais, adequandose, portanto,à valoração ético-social do caso concreto e de sua reprovabilidade quando do momento em que fora praticado o desvio (FERRÉ OLIVÉ; NUÑEZ PAZ; OLIVEIRA; BRITO, 2011, p. 89).Apesar de discutível, não há, para Jiménez de Asúa (1958, p. 151-152),incoerência nostais efeitos ultrativos em razão de serem diplomas criadosjustamente para situações de anormalidade.

\footnotetext{
11“un cambio cualitativo en el tratamiento de los Derechos Humanos, ya que se trata de instrumentos convencionales que imponen obligaciones jurídicas directamente vinculantes para los Estados-partes" Texto original Cf. VELASCO, Manuel Diez de. Las organizaciones internacionales. Madrid: Techos, 1996, p. 231.

${ }^{12}$ Art. $3^{\circ}$ - A lei excepcional ou temporária, embora decorrido o período de sua duração ou cessadas as circunstâncias que a determinaram, aplica-se ao fato praticado durante sua vigência.
} 


\title{
3 A JURISPRUDÊNCIA PENAL MAIS GRAVOSA E SUAS CONTROVÉRSIAS JURÍDICAS: BREVE CONTRIBUTO CRÍTICO SOBRE O ESTADO DA ARTE
}

No direito, assim como na vida, o decurso do tempo nos serve para determinar soluções. O tempo, aliás, é parâmetro basilar de um direitoque se pretende democrático. Dele depende uma série de estruturas do processo de regulação social (veja-se: OST, 2001). Com o direito penal, evidentemente, não poderia ser diferente. Seu regular funcionamento depende do uso adequado do elemento temporal.A medida da pena, a prescrição e até a conveniência da existência de um tipo legal de crime são reguladas tendo o tempo como seu principal parâmetro. Segundo François Ost (2001, p. 12):

\begin{abstract}
o tempo é uma instituição social antes de ser um fenómeno físico e uma experiência psíquica. Não há dúvida que ele apresenta uma realidade objectiva, tão bem ilustrada pelo curso das estrelas, pela sucessão do dia e da noite, ou pelo envelhecimento do ser vivo. Também é verdade que depende da experiência mais íntima da consciência individual que pode experienciar um minuto de relógio, ora como tempo interminável, ora como como instante fulgurante. [...] o tempo é antes do mais uma construção social - e, logo, uma questão de poder, uma exigência ética e um objecto jurídico.
\end{abstract}

De parte dessa relação do tempo no processo legislativo, ainda que de maneira palmar, por conta da natureza do presente trabalho, nos reportamos no capítulo anterior. Interessa-nos agora perceber essa relação quanto à interpretação judicial.Debruçaremos, pois, nossa atenção, dito mais especificamente, naquilo que se conceitua como:

o conjunto das decisões dos juízes e dos tribunais em que se recolhe a orientação por eles seguida na interpretação e aplicação das leis nos casos concretos ou nas hipóteses de ação direta de inconstitucionalidade de lei ou ato normativo federal ou estadual; a ação declaratória de constitucionalidade de lei ou ato normativo federal e a arguição de descumprimento de preceito fundamental (CF, art. 102, I $a$ e $\left.\S 1 .^{\circ}\right)$. (DOTTI, 2016, p. 252).

É, portanto, sobre a jurisprudência, notadamente a penal, que dedicaremos algumas reflexões a partir das linhas que seguem.

A consolidação das ideias liberais no Estado (dito) moderno não apenas consagrou a legalidade como um de seus parâmetros fundamentais, como também instituiu a separação dos poderes. Assim, de maneira sucinta, "caberia ao poder legislativo a feitura das leis incriminadoras e o poder judicial nada mais seria do que a «bouche de la loi»”. (COSTA; MOURA, 2016, p. 97)

Se no início a ideia da atividade judicial se constituía numa atuação quase que mecânica, de aplicação da lei (vide o código napoleônico - 1804) com base no privilégio de seu mero teor literal, contemporaneamente as coisas já não podem ser assim perspectivadas, sobretudo quando se constata um vertiginoso crescimento das leis penais (veja-se, por exemplo: GOMES; GAZOTO, 2016), com seus intérpretes tendendo à assunção de "um trabalho de correcção 
justicialista que introduz uma elevada dose de arbitrariedade e decisionismo na sua aplicação" (FARIA COSTA; MOURA, 2016, p. 96).

Nesse contexto, mesmo em países com forte tradição no civil law, como é o caso do Brasil, a jurisprudência, tradicionalmente forte em países da commom law, acabou galgando um espaço de imenso prestígio no sistema de controle e de punição. Na realidade, o que se tem observado ultimamente é uma confluência cada vez mais intensa entre ambos os modelos de sistema jurídico. ${ }^{13} \mathrm{~A}$ jurisprudência, portanto, em qualquer que seja o tipo de sistema, passou à condição de protagonista no debate sobre as fontes do direito penal, erodindo, de certa forma, o princípio da legalidade tal como prescrito nos diplomas até aqui citados.

As decisões do Supremo Tribunal Federal - para nos atermos à mais alta corte jurídica do país ,é inegável, têm provocado mudanças significativas nas estruturas que tradicionalmente sustentam o sistema penal brasileiro. Como apontado por René Ariel Dotti (2016, p. 255), por exemplo, a consolidação de julgados dos tribunais superiores já alcançou "repercussão geral para alterar ou compor disposições legais como ocorreu com as Leis 6.416, de 24.05.1977 e 7.209, de 11.07.1984, que consagram as Súmulas 146 (prescrição da ação penal pela pena concretizada)". Diversos outros exemplos são oferecidos como forma de se constatar que não é rara a criação de normas penais a partir da pacificação jurisprudencial.

A propósito, dado o contexto ora impregnado por um direito penal midático, tempos em que expressões como "operação lava-jato" 14 tendem a aparecer como legitimadoras de toda e qualquer iniciativa para o combate à impunidade dos crimes do colarinho branco (como se o discurso sobre o "combate à corrupção" justificasse praticamente tudo em termos processuais), o texto da lei que estabelece alguma garantia tem, não raramente, sido perspectivado como uma espécie de inconveninente obstáculo. Não por acaso, tribunais que deveriam se portar como verdadeiros e exigentes guardiões dos valores democráticos, cedem diante do argumento de que é preciso ir ao encontro da opinião pública(da).

Logo se vê que o tema da mudança de jurisprudência ganha ainda mais importância pelo protagonismo assumido pelo Supremo Tribunal Federal diante das cobranças sociais que se intensificaram, principalmente a partir de junho de 2013, por mudanças no funcionamento do

\footnotetext{
${ }^{13}$ Veja-se, como exemplo disso no Brasil, para além da súmula com efeito vinculante, a adoção, na sistemática processual civil, dos mecanismos oferecidos pelos precedentes. Não tardará e o processo penal brasileiro também há de se ver invadido por tais "inovações".

${ }^{14}$ Esse conjunto de investigações realizadas desde 2014sob o crivo da Justiça Federal em Curitiba/PR parecenos ter se constituído numa espécie de "passe livre" para a realização de toda sorte de arbitrariedades processuais, o que, evidentemente, tem servido também para justificar a provocação da doutrina e dos tribunais brasileiros numa tentativa de se estabelecer limites ao alegado "combate à corrupção".
} 
sistema político. O ativismo entusiasmadode alguns dos ministros da Corte é de nos fazer repensar seriamente o modelo constitucionalizado. Uma das propostas que tramitam no Congresso Nacional, que, da nossa perspectiva, pode agravar a falta de estabilidade na jurisprudência pátria, é o estabelecimento de mandatos para os ministros da Corte. ${ }^{15}$

Ademais, que a jurisprudência tenda a se alterar com o passar dos tempos não nos restam dúvidas. É uma constatação contra a qual, por óbvio, não nos insurgiremos. Da perspectiva de Alaor Leite $(2015$, p. 44), inúmeras são as razões que poderiam ser convocadas para uma alteração jurisprudencial: o avanço da técnica, a irrupção de fatos inéditos ou ainda alteração de valoração jurídica estão entre elas. Para o autor, quando há mudança, mesmo que gravosa, "parte-se do pressuposto de que o juiz movimentou-se dentro dos limites semâticos da lei, vale dizer: que ele respeitou a intensãodos termos legais e não praticou analogia”.

Até aqui, não nos parece difícil concluir, desde logo, que a retroatividade da juriprudência quando benéfica ao investigado é de ser não só possível como absolutamente recomendável. Se num determinado julgamento chegar-se, por exemplo, à conclusão de que aquele tipo de conflito não merece mais o status de crime, pois não é mais assim desvalorado socialmente, é de se entender que suas consequências jurídico-penais, independentemente do tempo, sejam estendidas aos casos análogos. Mas, repise-se, e quando o entendimento jurisprudencial for mais gravoso ao investigado? Existiria, ainda com Alaor Leite (2015, p. 45), "um direito do cidadão à jurisprudência do tempo do fato, tal como há em relação à lei vigente ao tempo do fato?”.

Segundo René Ariel Dotti (2016, p. 256), “a proibição da retroatividade da lei penal em prejuízo do réu deve ser entendida em sentido amplo, abracando também a jurisprudência”, justamente porque é uma “interpretação que da lei se faz”. Sustentar um entendimento no sentido contrário, na perspectiva de Juarez Cirino dos Santos (2008, p. 57), seria uma espécie de "lesão ao princípio da confiança nas manifestações dos Tribunais (porque a jurisprudência é a lei no caso concreto), com consequências para a vida real de seres humanos de carne e osso, equivalentes à retroatividade da lei penal em prejuízo do réu, proibida pela Constituição da República”.

Na mesma linha, em embasado estudo sobre o tema, Odone Sanguiné (2000, p. 162) ${ }^{16}$ assevera que essa proibição de retroatividade

se fundamenta na proteção da confiança dos cidadãos de que não vão ser surpreendidos por atuações arbitrárias não previstas nem previsíveis dos poderes estatais, desde o ponto de vista do indivíduo é psicologicamente indiferente que seja punido de forma

\footnotetext{
${ }^{15}$ A ideia já está posta através de substitutivo da Senadora Ana Amélia (PP-RS) na tramitação da PEC n. 44/2012, da qual ela é a relatora.

${ }^{16}$ Nessa passsagem o autor ainda aponta amparo em Fulgencio Madrid Conesa (1983, p. 93; 1982, p. 14-15).
} 
retroativa imprevista e imprevisível por causa de uma lei editada pelo Parlamento que não existia no momento de realizar o fato ou que se chegue a esse resultado através de uma nova interpretação jurisprudencial, decorrente de uma lei já existente, impossível de conhecer antes de sua declaração.

Apesar das mencionadas assertivas no sentido de indicar a taxativa proibição da retroatividade da jurisprudência mais gravosa aos casos ocorridos antes de sua declaração,que são, aliás, absolutamente coerentes com o sistema de proteção dos direitos humanos com o qual se relaciona o Brasil, a começar pelo disposto no art. 15 do Pacto Internacional sobre Direitos Civis e Políticos, existem ainda resistências que precisam ser enfrentadas para que aquelas mesmas sejam, se é que isso um dia virá a ser possível, encaradas também como uma obviedadenuma substancial democracia.

Desse modo, aqueles que se insurgem contra essa espécie de alargamennto da proibição da retroatividade para a jurisprudência penal mais gravosa, segundo o apanhado de Alaor Leite (2015, p. 54-62), alegam, basicamente que a) não há previsão legal para tal, que b) a decisão mais recente "seria a decisão correta, apenas tardiamente reconhecida", desde logo previsível ao investigado, que $c$ ) a "jurisprudência é essencialmente retroativa", "controvertida e fácil de ser alterada", e que $d$ ) "a estrutura do processo penal não comporta o alargamento da proibição da retroatividade para decisões judiciais". Há, no fundo, como indica o autor, uma preocupação com a "separação funcional entre legislação e jurisprudência - de modo que não se ponha em causa 'o próprio fundamento da separação de poderes'” (LEITE, 2015, p. 62).

O fato é que, contemporaneamente, conforme o apontado por Alaor Leite (2015, p. 53-54), apesar das resistências, o estado da arte nos oferece três consensos, além de uma "incerteza fundamental". São, portanto, os consensos: a) "a igualdade fática, desde a perspectiva do cidadão, quanto aos efeitos das alterações legislativas e jurisprudenciais"; b) a ideia de injustiça à "punição irrestrita do cidadão surpreendido, com o que se costuma mencionar", como solução, "o erro sobre a ilicitude"; e c) "a impossibilidade de ampliação irrestrita da proibição de retroatividade para toda e qualquer alteração jurisprudencial, com o que se causaria uma indesejávelpetrificação da jurisprudência”. Já a incerteza reside no tipo de critério que deverá ser adotado para uma possível admissão parcial dessa irretroatividade.

No Brasil, não é de hoje que a principal resitência à proibição da retroatividade da jurisprudência mais gravosa venha justamento do Supremo Tribunal Federal. Na situação mais emblemática, o plenário da mais alta Corte jurídica do país, por mais de uma vez, decidiu pela possibilidade da 
execução provisória da pena, contrariando o próprio texto constitucional. ${ }^{17}$ Além da violação ao que se compreende como presunção de inocência (ou não culpabilidade), não se percebiam ressalvas de que a decisão não poderia ser utilizada retroativamente. No entanto, num de seus momentos de aproximação mais intensa junto aos valores que se prestam a resguarda o Estado Democrático de Direito, no qual, aliás, a presunção de inocência é um pilar fundamental, em 2000, a Corte já havia decidido pela incompatibilidade constitucional da execução provisória da pena. $^{18}$

O fato é que, com o ainda recente julgamento do HC 126.292/SP, em 17 de fevereiro de 2016, os ministros do Supremo Tribunal Federal, em sua maioria, nesse constante movimento pendular, ${ }^{19}$ voltaram a considerar a execução provisória da penamedida como compatível com o texto constitucional, o que reascendeu o debate quer seja sobre a violação da presunção de inocência quer seja pela possibilidade de retroatividade do entendimento. Naquilo que nos interessa aqui, quanto à retroatividade da referida decisão,portanto, René Ariel Dotti (2016, p. 289) argumenta que tal decisão "não tem efeito retroativo para alcançar todos os recorrentes que ainda aguardam o desfecho de seus recursos".

Longe de ser um tema simples e, portanto, de possuirmos respostas definitivas para os questionamentos levantados a partir dele, da nossa perspectiva, a opção pela irretroatividade da jurisprudência mais gravosa parece-nos ser aquela que melhor se adequa aos valores democráticos encontrados nos diplomas locais, regionais e internacionais com os quais o Brasil tem se obrigado. Os argumentos apresentados para que se obste a pacificação desse tipo de entendimento, ao que nos consta, não se coadunam com o atual momento de conturbação sóciopolíticacom o qual convivemos. As acentuadas polarizações ideológicas (direita/esquerda) observadas desde a deflagração do impeachment da ex-presidente Dilma Rousseff,no lugar de arrefecerem após o término do processo eleitoral de 2018, foram intensificadas, exigindo-se do judiciário, e em especial do Supremo Tribunal Federal, por ter a última palavra,um esforço ainda maior para não se deixar contaminar.

\footnotetext{
${ }^{17}$ Art. $5^{\circ}$ - [...] LVII - ninguém será considerado culpado até o trânsito em julgado de sentença penal condenatória; Uma série de julgados sustentando a incolumidade do referido dispositivo mesmo com a execução provisória da pena é elencada em: DOTTI, 2016, p. 271. Em novembro de 2019 a Corte brasileira volta ao tema, agora no julgamento das Ações Declaratórias de Constitucionalidade (ADCs) 43, 44 e 54, decidindo pela constitucionalidade do artigo 283 do Código de Processo Penal, bem como pela inconstitucionalidade da execução provisória da pena, em posição a favor do princípio da presunção de inocência.

${ }^{18}$ Para ficarmos em um único exemplo: HC 79.812-8/SP.

19 “'O movimento pendular do Supremo, portanto, bate de frente com o conteúdo da Constituição Federal, tornando lamentável a decisão em análise. A solução apresentada é absolutamente inadequada, uma vez que tenta resolver as mazelas do Poder Judiciário às custas dos direitos e garantias fundamentais dos cidadãos". In: Editorial do Boletim do Instituto Brasileiro de Ciências Criminais, n. 282, abr., 2016.
} 
Assim, com uma Corte Suprema de justiça cujas decisões, em boa medida, têm sido tomadas ao sabor da opinião pública(da), por via de prudência, faz-se necessário que se estabeleçam determinados limites, especialmente a partir do (nem sempre hegemônico) trabalho doutrinal. A irretroatividade aqui exposta, na nossa perspectiva,é certamente um deles. Entretanto, que tais não se voltem, por exemplo, ao pleno exercício do direito de defesa, como com a edição da, ainda vigente, súmula n. 691, sendo esta amparada na ideia de não supressão de instância, com o condão de desestimular a provocação do andar de cima quando indeferido pedido liminar em Habeas Corpus. Além disso, as decisões dos tribunais superiores de não admitirem Habeas Corpus que tenham caráter de substitutos de recursos, o que era aceito "quando não havia a sobrecarga de processos que há hoje". ${ }^{20}$ Mais contemporaneamente, repise-se, vimos o debate sobre a presunção de inocência e a execução provisória da pena de prisão. Seja como for, mudanças como essas precisam seguir parâmetros de previsibilidade, confiança, boa-fé e, especialmente, de segurança jurídica.

\section{CONSIDERAÇÕES FINAIS}

Como foi possível antever, o tema que exploramos toca em questões sensíveis tanto da dogmática quanto da prática dos tribunais. $\mathrm{O}$ atual cenário de aproximação entre as estruturas normativas tradicionalmente utilizadas em países tributários dacommon lawe aquelas comuns aos adeptos da civil lawnos exige um dedicado esforço na tentativa de evitar que os limites erigidos historicamente contra o arbítrio sejam deliberadamente ultrapassados. ${ }^{21}$ Não é de hoje que, abarrotados de demandas, os tribunais brasileiros, os superiores em especial, com a indisfarçável cumplicidade do legislador, tem procurado reagiràs suas próprias ineficiências impondo inconvenientes obstáculos ao acesso à jurisdição.

Não é nosso intuito advogar qualquer tipo de imobilismo do sistema de justiça. Longe disso. Entretanto,diante de flagrantes excessos de ativismo judicial, é nosso dever estimular reflexões

20 "Guinada na jurisprudência - $1^{\text {a }}$ Turma do STF deixa de admitir HC substitutivo". In: Revista Consultor JurídicO, 8 de ago. 2012. Disponível em: https://www.conjur.com.br/2012-ago-08/turma-stf-deixa-admitir-hcsubstitutivo-recurso-ordinario. Acesso em: 31 abr. 2018.

${ }^{21}$ No Brasil, por exemplo, tradicionalmente adepto do civil law, com a vigência do Código de Processo Civil de 2015, viu-se a introdução do sistema de precedentes, muito comum nos países da common law. Para Mariângela Gama de Magalhães Gomes (2008, p. 144), "mais ofensiva à certeza jurídica que a lei imprecisa é a aplicação retroativa de um novo precedente. Isto porque, ao passo que a imprecisão da lei ainda permite ao jurisdicionado antecipar a possibilidade de determinada conseqüência jurídica, a alteração do precedente lhe traz o fator surpresa da mudança, já que a norma anteriormente especificada pelo Judiciário cede espaço para uma outra norma, concretizada após a prática de sua conduta". Trecho também citado em: SILVA, 2013, p. 126. 
críticas sobre expectáveiserosõesem direitos e garantias consagradas na Constituião da República e também nos intrumentos regionais e internacionais com os quais o país tem compromisso histórico.Nesse contexto, é compreensível que tanto a lei quanto a jurisprudência possam percorrer o tempo na tentativa de acompanhar as constantes mudanças impostas pela dinâmica social, o que não há de se admitir é que o judiciário, principal guardião dos valores democráticos, permita retrocessos que sejam desfavoráveis à proteção da dignidade da pessoa humana, fundamento máximo de um Estado Democrático de Direito.

Tal como Jano, porteiro celestial a quem a mitologia romana incumbiu a responsabilidade de ter suas duas faces contrapostas voltadas para passado e futuro simultaneamente, o judiciário deve, como é óbvio, manter-se vigilante esopesar todos os argumentos que lhes chegam, acolhendo-os, se possível, desde que se coadunem com as disposições do ordenamento e também com os compromissos regionais e internacionais assumidos pelo país (pacta sunt servanda). No entanto, só não lhe é dado utilizar o poder que possui para,de certa maneira, vulgarizar os paradigmas que sustentam umasubstancial democracia. Assim, permitir-se a retroatividade da jurisprudência de natureza penal, sendo ela prejudicial aos interesses do investigado, é, como vimos, um atentado à segurança jurídica, o que expõe o núcleofundante de um Estado Democrático de Direito, qual seja: a dignidade humana.

\section{REFERÊNCIAS}

BRASIL. Decreto-Lei 2.848, de 7 de setembro de 1940. Código Penal. Diário Oficial da República Federativa do Brasil. Brasília, 1940.

CALlEGARI, André Luis. Art. 5º XL. In: CANOTILHO, J. J. Gomes et al.Comentários a Constituição do Brasil. São Paulo: Saraiva/Almedina, 2013.

CHEVAlliER, Jacques. O Estado de Direito. Tradução: Antônio Araldo Ferraz dal Pozzo, Augusto Neves dal Pozzo. Belo Horizonte: Fórum, 2013.

CONESA, Fulgencio Madrid. La legalidad del delito. Valencia: Universidad de Valencia, 1983. CONESA, Fulgencio Madrid. El principio de irretroatividade de la Ley Penal y las variaciones jurisprudenciales desfavorables al reo. Valencia: Universidad de Valencia, 1982.

DOTTI, René Ariel. A jurisprudência penal no tempo: a ultratividade e a irretroatividade do julgado (HC 126.292/SP). In: Revista Brasileira de Ciências Criminais, São Paulo,ano 24, v. 121, jul. 2016. 
FARIA COSTA, José de; MOURA, Bruno. A interpretação em Direito Penal: um multiversum. In: Revista de Legislação e de Jurisprudência,ano 146,n. 4001, nov./dez. 2016.

FELDENS, Luciano. Direitos fundamentais e direito penal: garantismo, deveres de proteção, princípio da proporcionalidade, jurisprudência constitucional penal, jurisprudência dos tribunais de direitos humanos. Porto Alegre: Livraria do Advogado, 2008.

FERRÉ OLIVÉ, Juan Carlos; NUÑEZ PAZ, Miguel Ángel; OLIVEIRA, William Terra de; BRITO, Alexis Couto de. Direito penal brasileiro: parte geral, princípios fundamentais e sistema. São Paulo: Revista dos Tribunais, 2011.

GOMES, Luiz Flávio, GAZOTO, Luís Wanderley. Populismo penal legislativo:a tragédia que não assusta as sociedades de massas. Salvador: JusPodivm, 2016.

GOMES, Mariângela Gama de Magalhães. Direito penal e interpretação jurisprudencial: do princípio da legalidade às súmulas vinculantes. São Paulo: Atlas, 2008.

JIMÉNEZ DE ASÚA, Luis. La Ley y el Delito: principios de derecho penal. 3. ed. Buenos Aires: Abeledo-Perrot, 1958

KERSTING, Wolfgang. Universalismo e Direitos Humanos. Porto Alegre: EDIPUCRS, 2003.

LEITE, Alaor. Proibição de retroatividade e alteração jurisprudencial: a irretroatividade da jurisprudência constitutiva do injusto penal. In: Actas do colóquio O Direito Penal e o tempo. Coimbra: Instituto Jurídico, 2015.

LOPES, Dalliana Vilar; LOPES, Gills Vilar. A internalização dos tratados sobre Direitos Humanos na ordem jurídica brasileira e a problemática da ordem internacional. In: Universitas Relações Internacionais, Brasília, v. 14, n. 1, p. 51-59, jan./jun. 2016.

MUÑOZ CONDE, Francisco. Introducción al derecho penal. Montevideo/Buenos Aires: B de F, 2001.

OST, François. O tempo do Direito. Tradução: Maria Fernanda Oliveira. Lisboa: Instituto Piaget, 2001.

PORTELA, Paulo Henrique Gonçalves. Direito Internacional Público e Privado. 3. ed. Salvador: Juspodivm, 2011.

TOLEDO, Francisco de Assis. Princípios básicos de direito penal: de acordo com a Lei n. 7.209, de 11-07-1984 e com a Constituição Federal de 1988. 5. ed. São Paulo: Saraiva, 1994. 


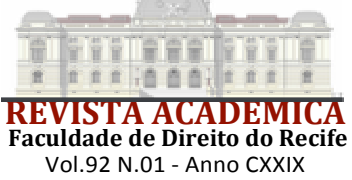

SANGUINÉ, Odone. Irretroatividade e retroatividade das alterações da jurisprudência penal. Revista Brasileira de Ciências Criminais, SãoPaulo,v. 31, ano 8, jul./set, 2000.

SANTOS, Juarez Cirino dos. Direito penal:parte geral. 3. ed. Curitiba: ICPC/Lumen Juris, 2008.

SILVA, Bruno Nova. A (ir)retroatividade das alterações jurisprudenciais: uma nova leitura do princípio da legaildade penal em meio à teoria dos precedentes. Dissertação (Mestrado em Direito) - Universidade Federal da Bahia, Salvador, 2013.

BRASIL. Supremo Tribunal Federal. Habeas Corpus n. 126.292/SP. Relator Ministro Teori Zavascki. DJ, 17 de fevereiro de 2016.

BRASIL. Supremo Tribunal Federal. Habeas Corpus n. 79.812-8/SP. Relator Ministro Celso de Mello. DJ, 8 de novembro de 2000.

VELASCO, Manuel Diez de. Las organizaciones internacionales. Madrid: Techos, 1996.

WEIS, Carlos. Os direitos humanos contemporâneos. São Paulo: Malheiros, 2006.

ZAFFARONI, Eugênio Raul; PIERANGELI, José Henrique. Manual de direito penal brasileiro: parte geral. 11. ed. São Paulo: Revista dos Tribunais, 2015. 